Stephen Halpern MD FRCPC,* Phyllis Glanc MD FRCPC, $\dagger$ Terri Myhr MSc, $\ddagger$ Marylou Ryan RDMs, $\ddagger$

Katherine Fong MB BS FRCPC, $\dagger$

Kofi Amankwah MD FRCsC, $\S$

Arne Ohlsson MD MSc FRCPC $\ddagger$

\title{
Uterine and umbilical blood flow velocity during epidural anaesthesia for Caesarean section
}

\begin{abstract}
The purpose of this study was to use colour Doppler to determine the effect of epidural anaesthesia on the uterine and umbilical blood flow velocities. After determining the precision of the technique, Doppler insonation of the uterine and umbilical arteries was performed in consenting non-labouring patients requesting epidural anaesthesia for Caesarean section. Patients in Group I were normal and those in Group II were at high risk for uteroplacental blood flow abnormalities. The pulsatility indexes (PI) of both uterine and umbilical arteries were compared at the following times: control, after fluid and after anaesthesia using repeated measure analysis of variance. In Group I $(n=30)$ the PI increased from 0.72 to 0.82 in the lefi uterine artery and from 0.71 to 0.85 in the right uterine artery $(P<0.05)$. In Group II $(n=10)$ the PI increased from 0.67 to 0.85 in the left uterine artery (NS) and from 0.98 to 1.38 in the right uterine artery $(P<0.05)$. There was no change in the PI in the umbilical artery. We conclude that the PI of the uterine arteries increases after epidural anaesthesia with lidocaine, epinephrine and fentanyl but there is no change in the umbilical PI. While these changes do not appear to be clinically important in the low-risk population, further studies are required to determine the impact on fetuses at high risk for in utero hypoxaemia.
\end{abstract}

\section{Key words \\ ANAESTHESIA: obstetrical; \\ ANAESTHESIA TECHNIQUES: epidural; \\ MEASUREMENT TECHNIQUES: Doppler ultrasound; UTERUS: blood flow velocity.}

From the Departments of Anaesthesia*, Radiology $\dagger$, Clinical Epidemiologył, and Obstetrics and Gynaecology§, Women's College Hospital, Toronto, Ontario.

Address correspondence to: Dr. S. Halpern, Department of Anaesthesia, Women's College Hospital, 76 Grenville St., Toronto,, Ontario Canada M5S 1B2.

Accepted for publication 22nd July, 1994.
L'objectif de ce travail consiste à utiliser le Döppler en couleur pour évaluer les répercussions de l'anesthésie épidurale sur les vélocités des flux sanguins utérin et ombilical. Après avoir démontré la précision de la technique, le sondage au Döppler des artères utérines et ombilicales est réalisé chez des parturientes programmées pour une césarienne qui sans être en travail ont choisi une épidurale pour lintervention. Les parturientes du groupe I étaient normales mais celles du groupe II représentaient un risque élevé d'anomalies du débit utéroplacentaire. Lindice de pulsatilité (IP) des artères ombilicale et utérine est comparé aux étapes suivantes: contrôle, après remplissage et après l'anesthésie avec la mesure répétée d'analyse de variance. Dans le groupe I $(n=30)$, l'IP augmente de 0,72 à 0,82 dans l'artère utérine gauche et de 0,71 à 0,85 dans l'artère utérine droite $(P<0,05)$. Dans le groupe $I I(n=10)$, l'IP augmente de 0,67 à 0,85 dans l'artère utérine gauche (NS) et de 0,98 à 1,38 dans l'artère utérine droite $(P<0,05)$. L'IP ne change pas dans l'artère ombilicale. Nous concluons que I'IP des artères utérines augmente après l'anesthésie épidurale avec la lidocaïne, épinéphrine et fentanyl mais que l'IP ombilical ne change pas. Bien que ces changements semblent ne pas d'importance clinique dans une population à faible risque, dans l'avenir, des études seront nécessaires pour déterminer l'impact de l'hypoxémie intra-utérine sur le foetus à risque élevé.

Obstetrical anaesthesia presents unique problems to the anaesthetist because the anaesthetic affects both the mother and fetus directly and indirectly. The ideal anaesthetic must be safe and effective for the mother and preserve uterine blood flow to ensure fetal oxygenation. Fetal oxygenation depends on the transfer of oxygen from the mother to the fetus and therefore is dependent on both the uterine and umbilical circulations. Both should be unchanged or improved by the anaesthetic to increase oxygen reserves at the time of birth.

Doppler ultrasound provides a measure of blood flow velocity through a blood vessel. Investigators have used this method to measure the effect of regional anaesthesia on umbilical and uterine blood flow velocities in humans 
and found no change, ${ }^{1,2}$ a reduction, ${ }^{3}$ and an increase ${ }^{4}$ when pre-anaesthetic levels are compared to postanaesthesia. In this study we used colour Doppler to assess the effect of epidural anaesthesia on the uterine and umbilical artery blood flow velocities in patients undergoing caesarean section. The use of colour adds to the precision of the technique because the anatomy of the blood vessels is more easily identified. We studied the effects of epidural anaesthesia using carbonated lidocaine, fentanyl and epinephrine on the pulsatility index (PI) of these vessels in patients with normal and abnormal pregnancies.

\section{Methods}

The study was approved by the Research Ethics Board of Women's College Hospital and informed consent was obtained from all participants.

The study was done in two parts. In Part I, we established the precision of the technique by comparing the reproducibility between two trained observers. Sixty patients including outpatients and inpatients at 26-37 wk gestational age were enrolled. Patients were placed in the supine position with a standard wedge under the right hip, tilting the patient $15^{\circ}$. Colour Doppler imaging (CDI) of the umbilical artery, and the right and left uterine arteries was performed by a radiologist (PG) and an experienced Doppler technician (MLR) via the abdominal wall. An ATL Ultramark 9 with a $3.5 \mathrm{MHz}$ convex array transducer was utilized. The acoustic power was kept to a minimum level according to FDA guidelines. The two observers performed their Doppler scans within $15 \mathrm{~min}$ of each other.

Imaging of the umbilical artery was performed 1 to $2 \mathrm{~cm}$ from the placental insertion site. 5,6 The uterine arteries were insonated $1-2 \mathrm{~cm}$ from the origin of the internal iliac arteries. ${ }^{6}$ The vessels were initially localized with the aid of colour Doppler and subsequently duplex Doppler imaging was performed. In order to avoid falsely elevating the flow velocity values, minimal surface pressure was applied when insonating the uterine arteries. Occasionally, pressure was applied to attempt to move overlying bowel gas. This pressure was then released and the CDI subsequently performed. Flow velocity waveforms were recorded on videotape for later analysis and

\section{DEFINITION OF TERMS}

Peak systolic flow $(\mathrm{PS})=$ Velocity $\left(\mathrm{cm} \cdot \mathrm{sec}^{-1}\right)$ at peak systole on the spectral trace.

End diastolic flow $(\mathrm{ED})=$ Velocity $\left(\mathrm{cm} \cdot \mathrm{sec}^{-1}\right)$ at the lowest point of a diastole on the spectral trace.

Mean blood flow velocity $\left(\mathrm{V}_{\text {mean }}\right)=$ The time average of the maximum Doppler velocity over the cardiac cycle.

Pulsatility index $(\mathrm{PI})=(\mathrm{PS}-\mathrm{ED}) /\left(\mathrm{V}_{\text {mean }}\right)$. the measurements of six consecutive cardiac cycles were averaged. ${ }^{7}$ The pulsatility index was then calculated as per the definitions above.

The precision of the technique was determined using the intraclass correlation coefficient (ICC) ${ }^{8}$ to determine interobserver agreement of the PI readings on all three vessels. Both the point estimate and the lower $95 \%$ confidence limit of the ICC were calculated.

The second part of the study consisted of consecutive nonlabouring patients requesting epidural anaesthesia for Caesarean section. Exclusion criteria included multiple gestation and emergency Caesarean section. Patients were studied in two groups: Group I were patients with no risk factors for abnormal uterine or umbilical blood flow and Group II were patients at high risk for such abnormalities by history.

The patient was admitted to the operating room and had the following monitors applied: an automatic blood pressure cuff, pulse oximeter, and ECG. The end tidal $\mathrm{CO}_{2}$ and the maternal respiratory rate were measured via a nasal cannula. All maternal physiological measurements were recorded automatically via a computer attached to the monitor. The epidural catheter was inserted in the $\mathrm{L}_{2}-\mathrm{L}_{3}$ or $\mathrm{L}_{3}-\mathrm{L}_{4}$ interspace and the patient positioned with $15^{\circ}$ left lateral tilt. Oxygen was given at $4 \mathrm{~L} \cdot \mathrm{min}^{-1}$ via a nasal cannula and $1000-1500 \mathrm{ml}$ Ringer's lactate was infused $i v$. A $3 \mathrm{ml}$ test dose of carbonated lidocaine $2 \%$ with $5 \mu \mathrm{g}$-epinephrine $\mathrm{ml}^{-1}$ and $50 \mu \mathrm{g}$ fentanyl was then given. Three minutes later, $5 \mathrm{ml}$ aliquots of the same local anaesthetic mixture were given until a $\mathrm{T}_{4}$ level of anaesthesia was obtained. A maximum dose of $100 \mu \mathrm{g}$ of epinephrine was used. Maternal blood pressure was taken every three minutes. If the systolic blood pressure was $20 \%$ below control or less than $100 \mathrm{mmHg}$, $5 \mathrm{mg}$ boluses of ephedrine were given to return blood pressure to the baseline. Doppler insonation measurements of the umbilical artery, right uterine artery and left uterine artery were obtained (1) after positioning of the patient (control), (2) after the fluid had been given (post-fluid) and (3) after the anaesthetic was effective (post-anaesthesia) to a $T_{4}$ level. All measurements were performed by the same individual (MLR). All Doppler observations performed in the same fashion as in Part $I$ of the study and were recorded on video tape for later analysis with a minimum of six cardiac cycles per artery.

The major outcome variable was the PI for the uterine and umbilical arteries. Apgar scores and cord gases were recorded as neonatal outcome variables.

\section{Statistics}

Interobserver agreement was calculated using the ICC.

Sample size was determined using data for expected 
TABLE I Pulsatility indexes of two observers and the intraclass correlation coefficient

\begin{tabular}{lllll}
\hline $\begin{array}{l}\text { Insonation } \\
\text { site }\end{array}$ & $\begin{array}{l}\text { Observer } \\
\# 1\end{array}$ & $\begin{array}{l}\text { Observer } \\
\# 2\end{array}$ & $\begin{array}{l}\text { Difference } \\
\text { between } \\
\text { observers }\end{array}$ & $\begin{array}{l}\text { Intraclass } \\
\text { correlation } \\
\text { coefficient }\end{array}$ \\
\hline Right uterine & $0.72(0.20)$ & $0.78(0.28)$ & $0.04(0.24)$ & $0.92(0.88)$ \\
Left uterine & $0.77(0.29)$ & $0.83(0.32)$ & $0.06(0.20)$ & $0.89(0.84)$ \\
Umbilical & $1.00(0.24)$ & $0.97(0.17)$ & $0.03(0.21)$ & $0.78(0.68)$ \\
\hline
\end{tabular}

Data are expressed as mean \pm S.D.

Data for the Intraclass Correlation Coefficient (ICC) are expressed as ICC ( $95 \%$ lower confidence limit).

TABLE Il Demographic data

\begin{tabular}{lll}
\hline & $\begin{array}{l}\text { Group 1 } \\
n=30 \\
\text { (normal) }\end{array}$ & $\begin{array}{l}\text { Group 2 } \\
n=10 \\
\text { (high risk) }\end{array}$ \\
\hline Factor & $32.5(4.2)$ & $29.2(6.1)$ \\
Maternal age (yr) & $38.6(0.95)$ & $33.9(4.95)$ \\
Gestational age (wk) & 33 & 20 \\
Breech (\%) & 82 & 60 \\
Multiparity (\%) & $4.8(1.3)$ & $4.8(1.1)$ \\
Level of epidural (thoracic segments) & $112(52)$ & $103(111)$ \\
Uterine incision to delivery time (sec) & $3477(493)$ & $2526(1816)$ \\
Fetal weight (g) & & \\
\hline
\end{tabular}

Mean \pm SD.

value of the PI from the literature. ${ }^{2}$ The sample size was set to detect a "medium size" change between control and post-anaesthesia in the ratio. This was calculated using the effect size index described by Cohen - "d." This parameter is defined as $\left(M_{a}-M_{b}\right) / S$. In this study, $M_{a}$ was the initial value for PI, $M_{b}$ was the value for PI after the epidural was fully effective and $S$ was the standard deviation of either population (from Reference 2. These values were compared in a paired fashion before and after anaesthesia. Using these assumptions, a " $\mathrm{d}$ " of 0.5 and a two-tailed $\alpha$ level of $0.05,30$ patients would achieve a power of approximately $85 \% .^{9}$

The change in PI from the baseline (control) was compared in each patient to post-fluid and post-anaesthesia values using repeated measure analysis of variance.

The data were also analyzed according to whether or not the patient received ephedrine. Data were compared within treatment groups using repeated measure analysis of variance. A $P$ value of $<0.05$ was considered statistically significant.

\section{Results}

In Part I of the study there were 60 patients. The mean gestational age was 31.1 wk with a range between 26 and $37 \mathrm{wk}$. Of these, 13 were normal pregnancies. There were 30 patients with premature rupture of membranes or a history of premature labour, 18 with antepartum
TABLE III Newborn outcome

\begin{tabular}{lll}
\hline Factor & Group I & Group 2 \\
\hline Apgar 1 minute $<7$ & $2(7 \%)$ & $3(30 \%)$ \\
Apgar 5 minutes $<7$ & $0(0 \%)$ & $1(10 \%)$ \\
Umbilical artery pH & $7.27(0.07)$ & $7.25(0.06)$ \\
Umbilical artery $\mathrm{PCO}_{2}(\mathrm{mmHg})$ & $52.8(9.1)$ & $51.9(11.3)$ \\
Umbilical artery $\mathrm{PO}_{2}(\mathrm{mmHg})$ & $18.7(8.5)$ & $16.3(4.1)$ \\
Umbilical vein $\mathrm{pH}$ & $7.33(0.04)$ & $7.30(0.05)$ \\
Umbilical vein $\mathrm{PCO}_{2}(\mathrm{mmHg})$ & $45.6(5.8)$ & $42.8(8.0)$ \\
Umbilical vein $\mathrm{PO}_{2}(\mathrm{mmHg})$ & $29.9(7.17)$ & $26.5(5.8)$ \\
\hline
\end{tabular}

Mean \pm SD.

TABLE IV Maternal haemodynamic data

\begin{tabular}{llllll}
\hline & & & & & $\begin{array}{l}\text { Post- } \\
\text { anaesthesia }\end{array}$ \\
\hline Low risk & 30 & HR & $81(13)$ & $82(15)$ & $92(14) \dagger$ \\
& & mean BP & $93(8.0)$ & $90(9.5)$ & $87(12)$ \\
High risk & 10 & HR & $89(19)$ & $90(9.0)$ & $96(11)$ \\
& & mean BP & $111(12)$ & $108(20)$ & $91(21)^{*}$ \\
\hline
\end{tabular}

Mean \pm SD.

${ }^{*} P<0.05$ compared with post-fluid and control.

$\dagger P<0.01$ compared with post-fluid and control.

haemorrhage, two with oligohydramnios, two with intrauterine growth retardation, three with maternal hypertension, three with diabetes, and four with other medical conditions. Some patients had more than one condition. Table I shows the mean PI for each of the observers, the mean difference between the observers and the ICC. An ICC of 0.6 to 0.8 implies substantial correlation while an ICC of $>0.8$ signifies near-perfect agreement. ${ }^{10}$

In the second part of the study, 30 normal patients (Group I) and ten high-risk patients (Group II) were enrolled in the study. The ten high-risk patients included one postmature (42.5 weeks), six insulin-dependent diabetics, five preeclamptics and three intrauterine growth retardation (some patients had more than one condition). The demographic data for each group of patients are shown in Table II and newborn data are shown in Table III. Maternal haemodynamic data is shown in Table IV.

Because of technical problems such as the presence of a posterior placenta, maternal obesity, and oligohydramnios, not all patients had all three arteries insonated. The number of observations on each artery is shown in Tables V and VI. There was an increase in the PI in the right and left uterine arteries in Group I and on the right side in Group II $(P<0.05)$. In the low-risk group there was a 27\% increase between control and postanaesthesia ( $95 \%$ confidence interval $(\mathrm{CI})=15-39 \%)$ on the right and $19 \%$ increase $(95 \% \mathrm{CI}=8-30 \%)$ on the 
TABLE V Pulsatility indexes - High risk and low risk

\begin{tabular}{llllll}
\hline & n per site & Site of insonation & Initial & Post-fluid & Post-anaesthesia \\
\hline Low risk & 20 & Left uterine & $0.72(0.21)$ & $0.74(0.13)$ & $0.82(0.02)^{*}$ \\
$n=30$ & 25 & Right uterine & $0.71(0.21)$ & $77(0.21) \dagger$ & $0.85(0.24)^{*}$ \\
& 28 & Umbilical & $0.81(0.12)$ & $0.81(0.16)$ & $0.80(0.15)$ \\
High risk & 5 & Left uterine & $0.67(0.15)$ & $0.76(0.16)$ & $0.85(0.15)$ \\
$n=10$ & 8 & Right uterine & $0.98(0.45)$ & $1.01(0.53)$ & $1.38(0.8)^{*}$ \\
& 8 & Umbilical & $1.08(0.56)$ & $1.31(1.06)$ & $1.14(0.52)$ \\
\hline
\end{tabular}

Mean $\pm \mathrm{SD}$

$* P<0.05$ compared with post-fluid and control.

$\dagger P<0.05$ compared with control.

TABLE VI Pulsatility indexes - ephedrine and no ephedrine

\begin{tabular}{llllll}
\hline & n per site & Site of insonation & Initial & Post-fluid & Post-anaesthesia \\
\hline Ephedrine & 9 & Left uterine & $0.67(0.12)$ & $0.73(0.11)$ & $0.86(0.19)^{*}$ \\
$n=17$ & 15 & Right uterine & $0.78(0.33)$ & $77(0.18)$ & $0.97(0.54)^{*}$ \\
& 15 & Umbilical & $0.84(0.24)$ & $1.05(0.80)$ & $0.83(0.27)$ \\
No ephedrine & 16 & & & & \\
$n=23$ & 18 & Left uterine & $0.74(0.23)$ & $0.75(0.15)$ & $0.81(0.19)$ \\
& 20 & Right uterine & $0.79(0.30)$ & $0.87(0.40)^{*}$ & $0.99(0.47) \dagger$ \\
& Umbilical & $0.90(0.35)$ & $0.85(0.28)$ & $0.91(0.32)$ \\
\hline
\end{tabular}

Mean \pm SD.

$* P<0.05$ compared with control.

$\dagger P<0.05$ compared with post-fluid and control.

left $(P<0.05)$. There was also a $29 \%$ increase in the PI on the right side and a $30 \%$ increase on the left in Group II (95\% CI $7-52 \%$ on the right: $-7-52 \%$ on the left) but the change did not achieve statistical significance on the left probably because of an insufficient number of observations. There was a smaller increase in these indices after the fluid bolus but before the administration of the anaesthetic. This was statistically significant in the right uterine artery of the normal group (Table V). There was no change in the PI of the umbilical arteries of either group.

There were 11 normal (Group I) and six high-risk patients (Group II) who became hypotensive between the time the fluid bolus was given and the time of anaesthesia. Each of these was given between five and $20 \mathrm{mg}$ ephedrine. Since there were insufficient numbers of patients in each group to analyze separately, the results were pooled. The systolic blood pressure of all patients was within $20 \%$ of control at the time the final insonation was performed although there was a statistically significant fall in the diastolic blood pressure $(6.0 \mathrm{mmHg}, 95 \%$ CI $2.4-9.6 \mathrm{mmHg}$ ). The PI increased in both the patients that received ephedrine and those that did not. The difference was statistically significant in the right uterine PI in patients who did not receive ephedrine and on the left in patients who received ephedrine (Table VI).

\section{Discussion}

This study demonstrates that epidural anaesthesia using carbonated lidocaine, fentanyl and $5 \mu \mathrm{g} \cdot \mathrm{ml}^{-1}$ epinephrine, when given in the epidural space for Caesarean section, increases the PI of the uterine vessels in patients with normal pregnancies and those at high risk for abnormal uteroplacental perfusion. However, there was no change in umbilical artery PI. An increase in PI is consistent with increased downstream impedance in these vessels, provided severe hypotension is not present. "I

Doppler ultrasound has many advantages in the study of uteroplacental haemodynamics. It is non-invasive and does not require the use of radioactive isotopes. Previous studies have shown little intraobserver variation ${ }^{12}$ and this study has shown substantial to near perfect agreement between observers, signifying good reproducibility of results. However, in order to quantitate blood flow in volume per unit time, the cross-sectional area must be known. Since the exact angle of insonation cannot be determined with certainty in the arteries of interest, neither the actual blood flow nor the velocity along the blood vessel can be calculated. To overcome this problem the ratio of the observed peak systolic and end diastolic blood flow velocities is taken and reported as the S/D or A/ $B$ ratio. ${ }^{1,4,13}$ When the ratio is taken, the angle values cancel out mathematically. The value of the ratio in- 
creases when downstream impedance increases. "The PI is a mathematical manipulation that correlates well with the S/D ratio in normal pregnancies but gives a finite value when the diastolic flow velocity is zero often occurs in high-risk pregnancies. Therefore it can be seen that Doppler ultrasound produces an indirect measurement and should be considered qualitative.

There have been several approaches to studying uterine blood flow before and after regional anaesthesia noninvasively in humans. Hollmén et al., using radioactive xenon, showed a small increase in intervillous blood flow when ephedrine was used prophylactically and a small reduction in control patients when epidural anaesthesia was used for Caesarean section. ${ }^{14}$ The changes were not statistically significant. More recently, Skjölderbrand, using radioactive indium showed no change in uterine blood flow when bupivacaine alone was used ${ }^{15}$ but a reduction in flow when epinephrine was added. ${ }^{16}$

Doppler techniques have also been used extensively to measure the effect of regional anaesthesia on uterine and umbilical blood flow velocity ratios. Two studies reported a reduction in the peak systolic to end diastolic (S/D) ratio in the umbilical circulation ${ }^{4,18}$ but only one showed a reduction in velocity ratios in uterine vessels as measured either by the PI or the S/D ratio. ${ }^{4}$ The cause of this finding may have been excessive hypotension that occurred in this study rather than a reduction in downstream impedance. Other studies found no changes ${ }^{1,2,17,18}$ in either umbilical or uterine blood flow velocity ratios. Only two of the above trials used local anaesthetic with epinephrine. ${ }^{1,2}$ Spinal anaesthesia was used in one of the trials. ${ }^{17}$

Recently, Alahuhta et al. reported a randomized trial on high-risk parturients comparing the PI in the uterine and umbilical arteries before and after epidural anaesthesia for Caesarean section. ${ }^{3}$ This study showed no change in PI with bupivacaine alone but an increase in PI when epinephrine was added.

Ephedrine is the drug of choice to treat hypotension caused by regional anaesthesia in obstetrics. ${ }^{19}$ This study confirms that ephedrine, when used for this purpose, has no deleterious effect on either uterine or umbilical flow velocity ratios.

When Doppler techniques are employed, several problems in design may preclude a study from showing a difference before and after anaesthesia in velocity ratios when one may exist. The Doppler technique itself must be standardized to increase the consistency of the observations. The site of insonation must be standardized ${ }^{5}$ and there must be at least six cardiac cycles included in each reading.' These precautions will ensure the least amount of observation error. The anaesthetic management must also be consistent, particularly concerning the dose of drugs used, preloading with crystalloid fluid, treatment of hypotension and positioning the patients. Finally, the sample size must be large enough to have the power to detect a clinically significant difference in blood flow velocity ratio. Most of the studies to date have not described the Doppler technique in sufficient detail and none have had an adequate sample size to detect a clinically significant change in blood flow velocity ratios.

In summary, epidural anaesthesia for Caesarean section using $2 \%$ lidocaine, $100 \mu \mathrm{g}$ ephedrine, and $50 \mu \mathrm{g}$ of fentanyl increases the PI of the uterine vessels but not the umbilical blood vessels. This reflects an increase in resistance and therefore possibly reduction in uterine blood flow in both high-risk and low-risk patients. Ephedrine, when used to raise the maternal blood pressure to normal, does not cause further increase in the PI. Although these changes do not appear to be clinically important in the low-risk population, further studies are required to determine the impact on fetuses at high risk for in utero hypoxaemia.

\section{Acknowledgements}

We wish to acknowledge the support of the following funding organizations: Physicians' Services Incorporated, Hospital for Sick Children Foundation, ATL Canada Ltd, and the Garfield-Weston Foundation. We also wish to thank the Obstetricians at Women's College Hospital for their patients and their patience.

\section{References}

1 Morrow RJ, Rolbin SH, Ritchie JWK, Haley S. Epidural anaesthesia and blood flow velocity in mother and fetus. Can J Anaesth 1989; 36: 519-22.

2 Alahuhta S, Räsänen J, Jouppila R, Jouppila P, Hollmén $A I$. The effects of extradural bupivacaine with adrenaline for Caesarean section on uteroplacental and fetal circulation. Br J Anaesth 1991; 67: 678-82.

3 Alahuhta S, Räsänen J, Jouppila P, Jouppila R, Hollmén $A I$. Uteroplacental and fetal circulation during extradural bupivacaine-adrenaline and bupivacaine for Caesarean section in hypertensive pregnancies with chronic fetal asphyxia. Br J Anaesth 1993; 71: 348-53.

4 Giles $W B$, Lah FX, Trudinger BJ. The effect of epidural anaesthesia for Caesarean section on maternal uterine and fetal umbilical artery blood flow velocity waveforms. $\mathrm{Br} \mathrm{J}$ Obstet Gynecol 1987; 94: 55-9.

5 Mehalek KE, Rosenberg J, Berkowitz GS, Chitkara U, Berkowitz $R L$. Umbilical and uterine artery flow velocity waveforms. Effect of the sampling site on Doppler ratios. $\mathrm{J}$ Ultrasound Med 1989; 8: 171-6.

6 Abramowicz JS, Warsof SL, Arrington J, Levy DL. Doppler analysis of the umbilical artery. The importance 
of choosing the placental end of the cord. $J$ Ultrasound Med 1989; 8: 219-21.

7 Spencer JAD, Price J, Lee A. Influence of fetal breathing and movements on variability of umbilical Doppler indices using different numbers of waveforms. J Ultrasound Med 1991; 10: 37-41.

8 Streiner DL, Norman GR. Health Measurement Scales: A Practical Guide to Their Development and Use. Oxford: Oxford Medical Publications, 1989.

9 Cohen J. Statistical Power Analysis for the Behavioral Sciences. New York: Academic Press, 1977: 36.

10 Landis JR, Koch GG. The measurement of observer agreement for categorical data. Biometrics 1977; 33: 159-74.

11 Moore J. Assessment of the placental circulation (Editorial). Br J Anaesth 1991; 67: 671-2.

12 Spencer JAD, Price J. Intraobserver variation in Doppler ultrasound indices of placental perfusion derived from different numbers of waveforms. J Ultrasound Med 1989; 8: 197-9.

13 Lindblad A, Bernow J, Mars̃al $K$. Fetal blood flow during intrathecal anaesthesia for elective Caesarean section. $\mathrm{Br} \mathbf{J}$ Anaesth 1988; 61: 376-81.

14 Hollmén AI, Jouppila $R$, Jouppila P, Koivula A, Vierola $H$. Effect of extradural analgesia using bupivacaine and 2chloroprocaine on intervillous blood flow during normal labour. Br J Anaesth 1982; 54: 837-42.

15 Skjöldebrand A, Eklund J, Johansson H, et al. Uteroplacental blood flow measured by placental scintigraphy during epidural anaesthesia for Caesarean section. Acta Anaesthesiol Scand 1990; 34: 79-84.

16 Skjöldebrand A, Eklund J, Lunell N-O, Nylund L, Sarby $B$, Thornström $S$. The effect on uteroplacental blood flow of epidural anaesthesia containing adrenalin for Caesarean section. Acta Anaesthesiol Scand 1990; 34: 85-9.

17 Alahuhta S, Räsänen J, Jouppila R, Jouppila $P$, KangasSaarela T, Hollmen AI. Uteroplacental and fetal haemodynamics during extradural anaesthesia for Caesarean section. Br J Anaesth 1991; 66: 319-23.

18 Petrikovsky BM, Cohen $M$, Tancer $M L$. Uterine and umbilical blood flow during cesarean section under epidural anesthesia. Acta Obstet Gynecol Scand 1988; 67: 737-40.

19 Shnider SM, Levinson G. Cosmi EV. Obstetric anesthesia and uterine blood flow. In: Shnider SM, Levinson G (Eds.). Anesthesia for Obstetrics, 3rd ed. Baltimore: Williams \& Wilkins, 1993; 29-52. 